\title{
UDOSKONALENIA W RADIOTERAPII RAKA PIERSI ZAPREZENTOWANE PODCZAS KONFERENCJI ESTRO 37
}

\section{IMPROVING RADIATION THERAPY IN BREAST CANCER PRESENTED AT THE ESTRO 37 CONFERENCE}

\author{
Maria Olmińska ${ }^{1}$
}

${ }^{1}$ Zakład Fizyki Medycznej, Wielkopolskie Centrum Onkologii, Poznań, Polska

\section{Streszczenie}

Celem pracy jest przedstawienie przykładów udoskonaleń w radioterapii raka piersi, możliwych do osiągnięcia dzięki zastosowaniu nowoczesnych technologii, zaprezentowanych podczas konferencji ESTRO 37 w Barcelonie w Hiszpanii.

\begin{abstract}
The aim of this paper is to underline the most important aspects of improving radiation therapy in breast cancer using high technology. The described trends and some research problems were presented during ESTRO 37 conference in Barcelona, Spain.

Stowa kluczowe: rak piersi, DIBH, napromienianie na brzuchu

Keywords: breast cancer, DIBH, prone position

Jednym z tematów będących przedmiotem konferencji ESTRO 37, która odbyła się w dniach od 21 do 24 kwietnia 2018 roku w Barcelonie, były udoskonalenia w radioterapii raka piersi. Udoskonalenia, które pozwalają na redukcję dawki w tkankach zdrowych, a które są możliwe dzięki zastosowaniu nowoczesnych technologii. Przedstawiono szereg prac dotyczące napromieniania pacjentek na głębokim wdechu, na brzuchu, prace porównujące nowoczesne metody planowania leczenia oraz prace dotyczące obrazowania pacjentek przed napromienianiem. Na ich przykładzie oparty został niniejszy artykuł.
\end{abstract}

Adres do korespondencji

Maria Olmińska

Zakład Fizyki Medycznej,

Wielkopolskie Centrum Onkologii, ul. Garbary 15, 61-866 Poznań, Polska

Telefon. +48618850763

e-mail: maria.olminska@wco.pl 
Rak piersi jest najczęstszym nowotworem złośliwym u kobiet. Według Światowej Organizacji Zdrowia każdego roku odnotowuje się 2,1 miliona nowych zachorowań, a rak piersi wśród nowotworów jest najczęstszą przyczyną zgonów [1]. Ze względu na częstość zachorowań, coraz niższy wiek pacjentek i coraz dłuższy czas życia od momentu diagnozy leczenie raka piersi jest bardzo ważnym tematem.

Głównym celem wdrażania zaawansowanych technologii w radioterapii jest minimalizacja dawki w narządach krytycznych z zachowaniem konformalizacji i homogeniczności rozkładu dawki w objętości tarczowej. Ważne jest również, aby wprowadzane udoskonelenia były łatwe do zastosowania w praktyce klinicznej oraz tanie, aby móc je stosować na szeroką skalę.

$\mathrm{Na}$ konferencji ESTRO 37 odbyło się 5 wystąpień ustnych dotyczących udoskonaleń w radioterapii raka piersi. Główne zagadanienia omawiane na sesjach ustnych to:

- wykorzystanie technik dynamicznych takich jak IMRT (ang. Intensity Modulated Radiation Therapy), VMAT (ang. Volumetric Modulated Arc Therapy), terapii helikalnej czy zastosowanie terapii z wykorzystaniem promieniowania protonowego,

- napromienianie na głębokim wdechu (ang. Deep Inspiration Breath Hold, DIBH),

- napromienianie pacjentek w pozycji na brzuchu i na plechach (ang. Supine Position, Prone Position)

\section{Napromienianie na głębokim wdechu (DIBH)}

Celem techniki DIBH jest odsunięcie serca od ściany klatki piersiowej poprzez kontrolowane nabieranie i wstrzymywanie wdechu. Głęboki wdech powoduje, iż tkanka płuca się rozpręża i odsuwa serce od ściany klatki piersiowej. Zabieg taki pozwala geometrycznie oddalić (odizolować) serce od obszaru wysokiej dawki promieniowania, pozwala to na znaczną redukcję dawki w tym narządzie (ryc.1) [2,3]. Do przeprowadzenia techniki DIBH niezbędne są systemy do kontroli oddechowej w czasie rzeczywistym np. Real-time Position Managment $[3,4]$.

\section{Normal breathing Breath hold}

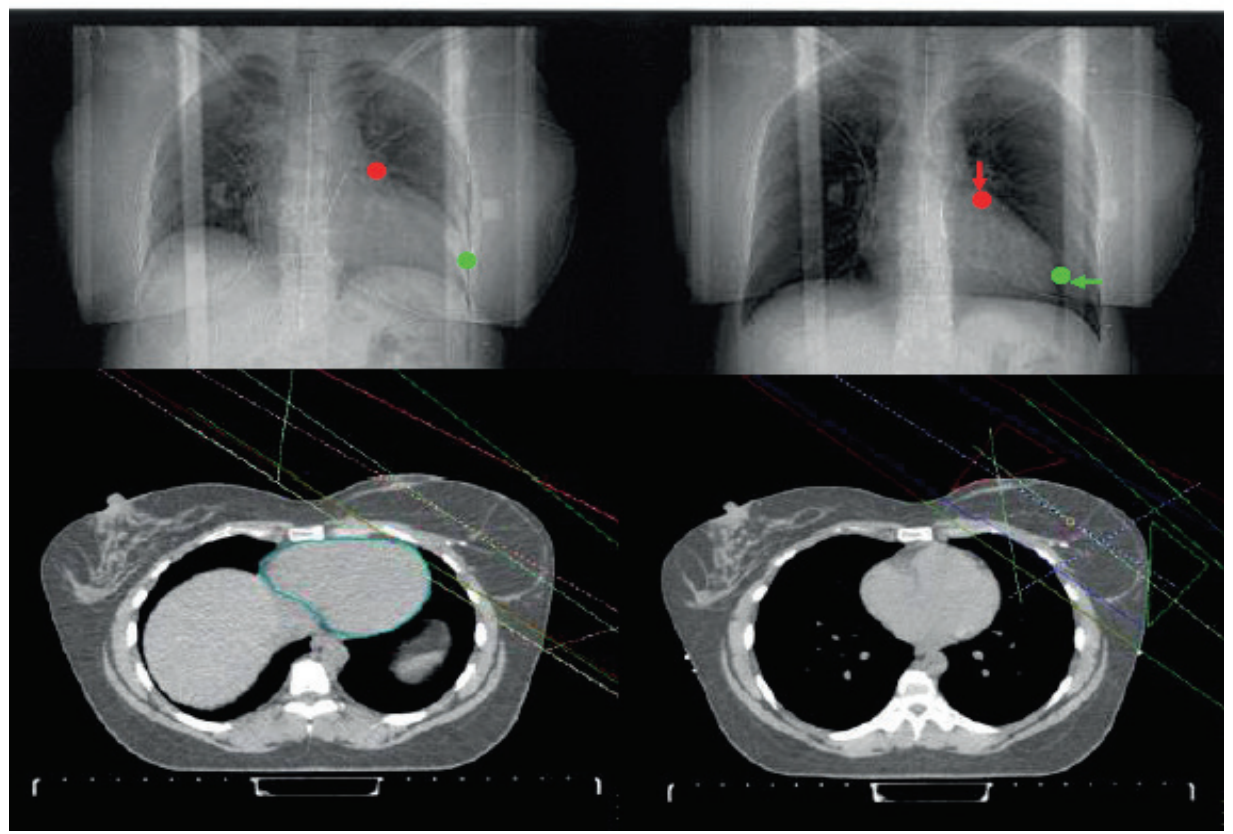

Ryc.1. Przekrój tomograficzny klatki piersiowej pacjentki przy: a) swobodnym oddychaniu i

b) głębokim wdechu, obrazujące odsunięcie się od klatki piersiowej serca [3].

Praca irlandzkich naukowców porównująca napromienianie na swobodnym oddechu FB (ang. Free breathing) $\mathrm{z}$ napromienianiem na głębokim wdechu zawierała dane 28 pacjentek $\mathrm{z}$ rakiem lewej piersi. Badanie to było retrospektywne - na podstawie przekrojów tomograficznych wykonano obrysy objętości tarczowej (PTV) i narządów krytycznych: płuca, płuco lewe, serce i lewą tętnice wieńcową (LTW) oraz 
zaplanowano w technice 3DCRT. Analiza opierała się na porównaniu dawek maksymalnych $\left(\mathrm{D}_{\max }\right)$ i średnich $\left(\mathrm{D}_{\text {mean }}\right.$ ) oraz parametrów V30 i V20, czyli objętości danej struktury jaka otrzymuje odpowiednio dawkę 30 Gy i 20 Gy. W planach na głębokim wdechu redukcja dawki wynosiła średnio 30\% dla płuc i serca oraz 50\% dla tętnicy w porównaniu z planami na swobodnym oddechu. Wszystkie wartości przedstawiono w tabeli 1. Zastosowanie techniki DIBH pozwalają ograniczyć dawkę w sercu i LWT, zmniejszy to ryzyko powikłań kardiologicznych w późniejszym okresie życia pacjentek $[5,6]$.

Tabela 1. Porównanie $\mathrm{D}_{\max }, \mathrm{D}_{\text {mean }}$ oraz V30 i V2o dla planów utworzonych na głębokim wdechu (DIBH) i na swobodnym oddechu (FB) [4].

\begin{tabular}{|c|c|c|c|}
\hline Parametr & Technika & Wartość średnia & $\begin{array}{c}\text { Odchylenie } \\
\text { standardowe }\end{array}$ \\
\hline \multirow{2}{*}{ Pluca $\mathrm{D}_{\max }[\mathrm{Gy}]$} & FB & 48,33 & 3,45 \\
\hline & DIBH & 48,37 & 3,13 \\
\hline \multirow[t]{2}{*}{ Pluca $\mathrm{D}_{\text {mean }}[\mathrm{Gy}]$} & FB & 3,74 & 1,79 \\
\hline & DIBH & 3,39 & 1,16 \\
\hline \multirow[t]{2}{*}{ Płuca V30 [\%] } & FB & 5,62 & 3,95 \\
\hline & DIBH & 4,91 & 2,23 \\
\hline \multirow[t]{2}{*}{ Płuca V20 [\%] } & FB & 6,61 & 4,49 \\
\hline & DIBH & 5,78 & 2,55 \\
\hline \multirow[t]{2}{*}{ Lewe płuco $\mathrm{D}_{\max }[\mathrm{Gy}]$} & FB & 48,33 & 3,45 \\
\hline & DIBH & 48,43 & 3,06 \\
\hline \multirow{2}{*}{ Lewe płuco $\mathrm{D}_{\text {mean }}[\mathrm{Gy}]$} & FB & 8,15 & 3,74 \\
\hline & DIBH & 7,16 & 2,38 \\
\hline \multirow{2}{*}{ Serce $\mathrm{D}_{\max }[\mathrm{Gy}]$} & FB & 41,81 & 3,96 \\
\hline & DIBH & 27,39 & 12,39 \\
\hline \multirow[t]{2}{*}{ Serce $\mathrm{D}_{\text {mean }}[\mathrm{Gy}]$} & FB & 1,82 & 0,63 \\
\hline & DIBH & 1,22 & 0,34 \\
\hline \multirow[t]{2}{*}{ Serce V3o [\%] } & $\mathrm{FB}$ & 0,47 & 1,03 \\
\hline & DIBH & 0,05 & 0,18 \\
\hline \multirow[t]{2}{*}{ Serce V20 [\%] } & FB & 0,89 & 1,18 \\
\hline & DIBH & 0,12 & 0,32 \\
\hline \multirow[t]{2}{*}{ LTW $D_{\max }[\mathrm{Gy}]$} & FB & 29,82 & 10,05 \\
\hline & DIBH & 15,56 & 10,62 \\
\hline \multirow[t]{2}{*}{ LTW D $_{\text {mean }}[\mathrm{Gy}]$} & FB & 10,88 & 3,95 \\
\hline & DIBH & 5,23 & 1,94 \\
\hline
\end{tabular}

Technika DIBH jest powszechnie stosowana w przypadku radioterapii lewej piersi [79]. Na konferencji ESTRO37 zaprezentowano dwie prace przedstawiające korzyści z zastosowania techniki głębokiego wdechu u pacjentek z rakiem prawej piersi. Zauważono u nich redukcję dawki w płucach oraz sercu. W przedstawionych pracach zaobserowano spadek współczynnika V17, czyli objętości serca jaka dostaje dawkę równą 17 Gy, z 33\% do 28\% oraz dawkę średnią dla płuc równą 3,4 Gy, gdy zazwyczaj wynosi ona około 7 Gy $[8,9]$. 


\section{Napromienianie pacjentek w pozycji na brzuchu i na plechach}

Abyzachowaćpowtarzalnośćpozycjipacjentanastoleterapeutycznymwtrakcieseansuradioterapeutycznego powszechnie stosuje się unieruchomienia oraz podstawki [10,11]. Powszechnie stosowanym ułożeniem pacjentki przy napromienianiu piersi jest pozycja na plecach [12].

Zagadanieniem, które szeroko umówiono na konferencji to napromienianie pacjentek w pozycji na brzuchu (ang. Prone Position). W tym celu pacjentkę układa się na specjalnej podstawce tak, aby pierś swobodnie (grawitacyjnie) wisiała w powietrzu. Rozwiązanie to zapewnia wysoką powtarzalność pozycji oraz zwiększony komfort szczególnie dla pacjentek z dużymi piersiami. Pierś pacjentki w tej pozycji dodatkowo jest unieruchomiona specjalnym stanikiem (ryc. 2) [13,14].
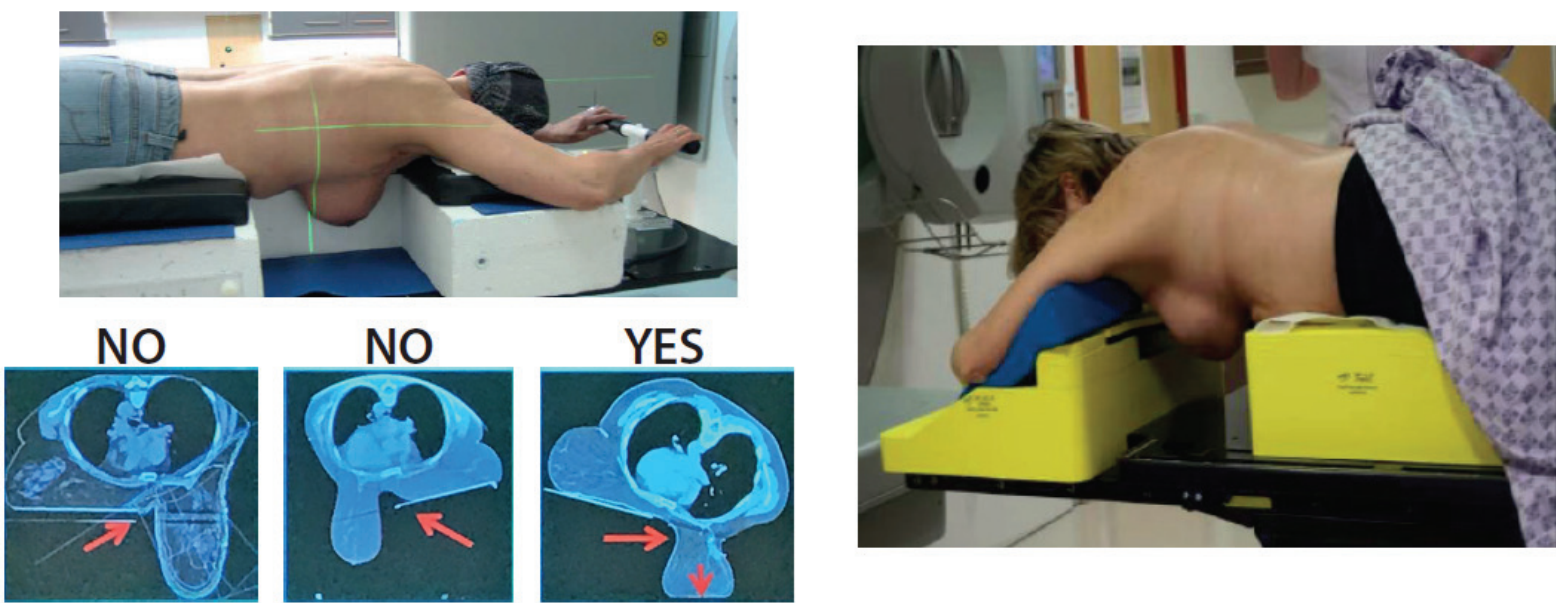

Ryc. 2. Ułożenie pacjentki przy napromienianiu na brzuchu [13].

Zastosowanie techniki DIBH wraz z pozycjonowaniem pacjentki na brzuchu pozwala dodatkowo ograniczać dawkę w sercu i płucach (ryc. 3). Jedna z zaprezentowanych na konferencji prac przedstawia porównanie rozkładów dawek dla pacjentek napromienianych w technice DIBH w pozycji na brzuchu i na plechach. Praca zawierała dane 51 pacjentek, wszystkim wykonano badanie tomograficzne w dwóch pozycjach. Porównano dawkę maksymalną, średnią oraz objętości V5 i V10 dla serca i dawkę średnią i maksymalną dla lewej tętnicy wieńcowej (tab. 2). Pozycja na brzuchu pozwoliła uzyskać bardziej korzystny rozkład dawki dla serca i lewej tęstnicy wieńcowej. Pozycja ta pozwoliła zredukować dawkę średnią w sercu z 2,2 Gy na 1,4 Gy. Zastosowanie takiego pozycjonowania pacjentek poprawiło odtwarzalność ułożenia pozycji na aparacie terapeutycznym [15].

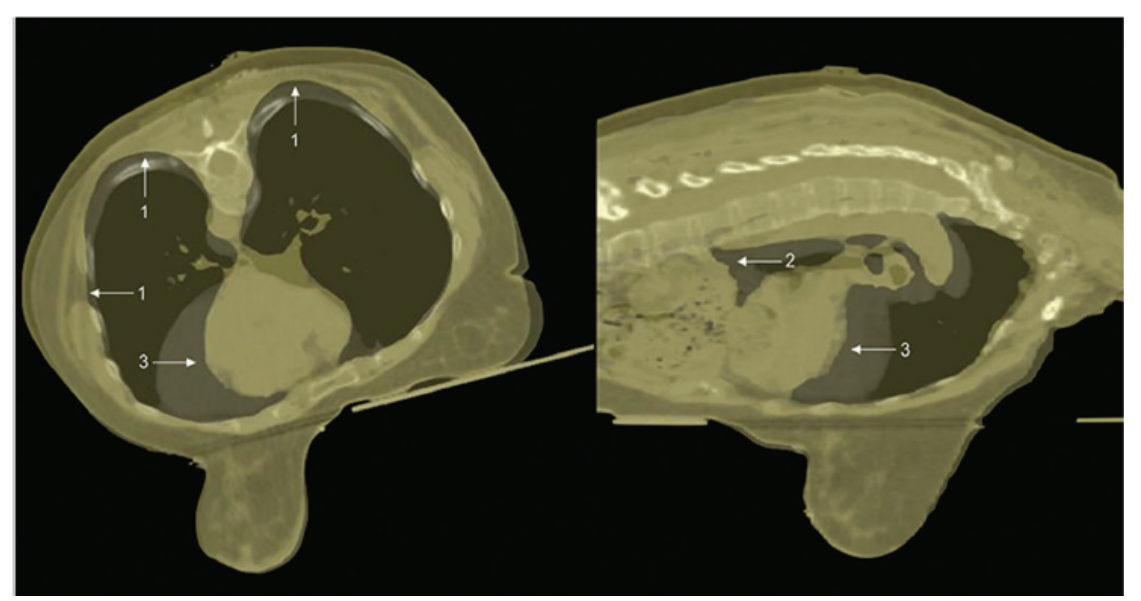

Ryc. 3. Zdjęcie przedstawiające ułożenie serca przy napromienianiu na brzuchu na głębokim wdechu [15]. 
Tabela 2. Porównanie $\mathrm{D}_{\max }, \mathrm{D}_{\text {mean }}$ oraz V5 i V10 dla serca oraz dla lewej tętnicy wieńcowej dla pozycji na plecach i na brzuchu.

\begin{tabular}{|c|c|c|c|c|}
\hline & \multicolumn{2}{|c|}{ Pozycja na plecach } & \multicolumn{2}{c|}{ Pozycja na brzuchu } \\
\hline Parametr & Wartość średnia & $\begin{array}{c}\text { Odchylenie } \\
\text { standardowe }\end{array}$ & Wartość średnia & $\begin{array}{c}\text { Odchylenie } \\
\text { standardowe }\end{array}$ \\
\hline Serce $\mathrm{D}_{\max }[\mathrm{Gy}]$ & 14,6 & 12,0 & 5,3 & 2,0 \\
\hline Serce $\mathrm{D}_{\text {maan }}[\mathrm{Gy}]$ & 2,2 & 1,2 & 1,4 & 0,4 \\
\hline Serce V5 $[\%]$ & 5,5 & 5,0 & 2,1 & 1,4 \\
\hline Serce V10 $[\%]$ & 3,4 & 4,0 & 0,7 & 0,6 \\
\hline LTW D & 12,4 & 14,9 & 6,6 \\
\hline LTW $\mathrm{D}_{\max }[\mathrm{Gy}]$ & 25,5 & 7,8 & 4,1 & 1,6 \\
\hline
\end{tabular}

Pracą podsumuwującą analizę napromieniania piersi w różnych technikach jest praca, która powstała przy współpracy kilku brytyjskich ośrodków. Materiał składał się z danych 14 pacjentek, których mediana wieku wynosiła 57 lat. Każda z nich miała wykonane dwa badania tomograficzne: na swobodnym oddechu i na wdechu. Na podstawie uzyskanych przekrojów tomograficznych przygotowano siedem niezależnych planów w różnych technikach: na swobodnym oddechu: 3DCRT, VMAT, protony i terapia helikalna oraz na wdechu: 3DCRT, VMAT i protony. Łącznie porównano 98 planów. Przeanalizowano różnice w rozkładach dawek. W badanej grupie najbardziej konformalny rozkład uzyskano z wykorzystaniem promieniowania protonowego (ryc. 4). Znacząco lepsze pokrycie PTV izodozą 90\% dawki zadanej uzyskano dla technik VMAT na wdechu i protonów zarówno na swobodnym oddechu jak i na wdechu.

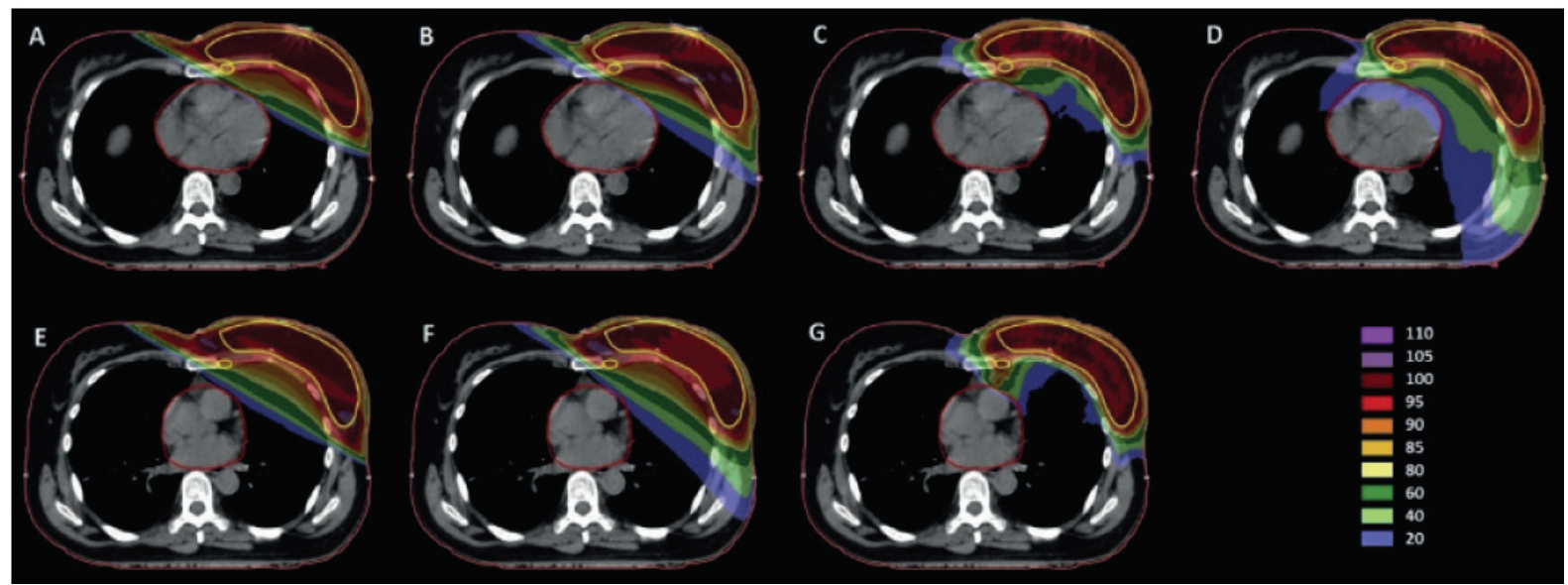

Ryc. 4. Rozkład dawki dla planów wykonanych na swobodnym oddechu w technikach: A - 3DCRT, B - VMAT, $\mathrm{C}$ - protony, D - terapia helikalna oraz na głębokim wdechu: E - 3DCRT, F - VMAT, G - protony [2,16].

Przeanalizowano dawki w narządach krytycznych. Wszystkie plany z przygotowanych 98 planów leczenia spełniały określone warunki i były akceptowalne klinicznie. Największą redukcję dawki dla serca i płuc uzyskano dla planów na wdechu. Statystycznie znaczące różnice uzyskano dla technik 3DCRT i VMAT [17,18].

Nie było różnic dla protonoterapii na wdechu i na swobodnym oddechu zarówno dla objętości tarczowej i narządów krytycznych. Technika okazała się najlepsza pod każdym kątem analizowanych parametrów $[2,9,16]$.

Podsumowując tytułowy temat, napromienianie na głębokim wdechu w technice 3DCRT pozwala uzyskać satysfakcjonujące pokrycie obszaru tarczowego przy jednoczesnej ochronie serca i płuc. Ponadtojest to metoda najtańsza i najłatwiejsza do realizacji ze wszystkich omówionych. Jeśli nie osiągnie się satysfakcjonującego pokrycia PTV w tym przypadku, wtedy optymalnym rozwiązaniem jest technika VMAT na wdechu. 


\section{Konflikt interesu/Conflict of interest}

Nie występuje.

\section{Finansowanie/Financial support}

Praca była finansowana z grantu Wielkopolskiego Centrum Onkologii w Poznaniu./Thiswork was supported by the Greater Poland Cancer Centre.

\section{Etyka/Ethics}

Treści przedstawione w artykule są zgodne z zasadami Deklaracji Helsińskiej, dyrektywami EU oraz ujednoliconymi wymaganiami dla czasopism biomedycznych.

\section{Piśmiennictwo/References}

[1] https://www.who.int/cancer/prevention/diagnosis-screening/breast-cancer/en/;

[2] C. Bergom, a. Currey, N. Desai, A. Tai, J. Strauss, Deep Inspiration Breath Hold: Techniques and Advantages for Cardiac Sparing During Breast Cancer Irradiation, Front Oncol. 2018 Apr 4;8:87;

[3] G. Lawner, M. Leech, Dose sparing potential of deep inspiration breath-hold technique for left breast cancer radiotherapy organs-at-risk, Anticancer Res. 2017 Feb;37(2):883-890;

[4] A. Kirby, Cost-effective implementation of respiratory control for all, materiały zjazdowe konferencji ESTRO 37, Barcelona, 21-24.04.2018;

[5] C. Bergom, a. Currey, N. Desai, A. Tai, J. Strauss, Deep Inspiration Breath Hold: Techniques and Advantages for Cardiac Sparing During Breast Cancer Irradiation, Front Oncol. 2018 Apr 4;8:87;

[6] S. Register, C. Takita, I. Reis, W. Zhao, W. Amestoy, J. Wright, Deep inspiration breath-hold technique for left-sided breast cancer: An analysis of predictors for organ-at-risk sparing, Med Dosim. 2015 Spring;40(1):89-95;

[7] J. Lai, S. Hu, Y. Luo, R. Zheng, Q. Zhu, P. Chen, B. Chi, Y. Zhang, F. Zhong, X. Long, Meta-analysis of deep inspiration breath hold (DIBH) versus free breathing (FB) in postoperative radiotherapy for leftside breast cancer, Breast Cancer 2020 Mar;27(2):299-307;

[8] N. Desai, A. Currey, T. Kelly, C. Bergom, Nationwide Trends in Heart-Sparing Techniques Utilized in Radiation Therapy for Breast Cancer, Adv Radiat Oncol. 2019 Jan 30;4(2):246-252;

[9] A. Ranger, A. Dunlop, K. Hutchinson, H. Convey, M. Maclennan, H. Chantler, N. Twyman, C. Rose, D. McQuaid, R. Amos, C. Griffin, N. deSouza, E. Donovan, E. Harris, C. Coles, A. Kirby, A dosimetric comparison of breast radiotherapy techniques to treat

[10] locoregional lymph nodes including the internal mammary chain, Clin Oncol (R Coll Radiol). 2018 Jun;30(6):346-353.

[11] E. Wiesendanger-Wittmer, N. Sijtsema, C. Muijs, J. Beukema, Systematic review of the role of a belly board device in radiotherapy delivery in patients with pelvic malignancies, Radiother Oncol. 2012 Mar;102(3):325-34;

[12] C. Hansen, R. Christiansen, T, Nielsen, A. Bertelsen, J. Johansen, C. Brink, Comparison of three immobilisation systems for radiation therapy in head and neck cancer, Acta Oncol. 2014 Mar;53(3):4237

[13] P. Deseyne, B. Speleers, W. De Neve, B. Boute, L. Paelinck, T. Van Hoof, J. Van De Velde, A. Van Greveling, C. Monten, G. Post, H. Depypere, L. Valdeman, Whole breast and regional nodal irradiation in prone versus supine position in left sided breast cancer, Radiat Oncol. 2017 May 26;12(1):89;

[14] M. Aznar, Avoiding side effects: getting the best out of advanced delivery techniques, materiały zjazdowe konferencji ESTRO 37, Barcelona, 21-24.04.2018;

[15] Buijsen, J. Jager, J. Bovendeerd, R. Voncken, J. Borger, L. Boersma, L. Murrer, P. Lambin, Prone

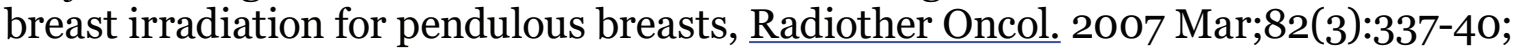


[16] T. Mulliez, J. Van de Velde, L. Veldeman, W. De Gersem, T. Vercauteren, B. Speleers, H. Degen, J. Wouters, T. Van Hoof, A. van Greveling, C. Monten, D. Berwouts, W. De Neve, Deep inspiration breath hold in the prone position retracts the heart from the breast and internal mammary lymph node region, Radiother Oncol. 2015 Dec;117(3):473-6;

[17] F. Kara, A. Haydaroglu, H. Eren, G. Kitapcioglu, Comparison of Different Techniques in Breast Cancer Radiotherapy Planning, J Breast Health. 2014 Apr 1;10(2):83-87.

[18] M. Sakka, L. Kunzelmann, M. Metzger, G. Grabenbauer, Cardiac dose-sparing effects of deepinspiration breath-hold in left breast irradiation : Is IMRT more beneficial than VMAT?, Strahlenther Onkol. 2017 Oct;193(10):800-811;

[19] T. Pham, R. Ward, D. Latty, C. Owen, V. Gebski, J. Chojnowski, C. Kelly, V. Ahern, K. Tiver, K. Stuart, W. Wang, Left-sided breast cancer loco-regional radiotherapy with deep inspiration breath-hold: Does volumetric-modulated arc radiotherapy reduce heart dose further compared with tangential intensity-modulated radiotherapy?, J Med. Imaging Radiat Oncol. 2016 Aug;60(4):545-53; 